\title{
THE CORRELATION OF SURFACE MORPHOLOGY TO THE HHO GENERATOR GAS PRODUCTION
}

\author{
AJAT SUDRAJAT ${ }^{1}$, NOREFFENDY TAMALDIN ${ }^{2}$, AHMAD KAMAL MAT YAMIN ${ }^{3} \&$ MUHD $^{2}$ \\ RIDZUAN MANSOR ${ }^{4}$ \\ ${ }^{1}$ Faculty of Engineering and Science, Universitas Nasional-Jakarta, JL. Sawo Manila, Pasar Minggu, Jakarta 12520, Indonesia \\ ${ }^{2,3,4}$ Center of Advance Research and Energy CARe, Faculty of Mechanical Engineering, Universiti Teknikal Malaysia Melaka,
} Hang Tuah Jaya, 76100 Durian Tunggal, Melaka, Malaysia

\section{ABSTRACT}

Of the many stainless-steel plates used for electrodes, typically HHO generator utilized a $316 \mathrm{~L}$ stainless steel which is a low-carbon material and the properties depend on the oxide layer on its surface (Lodhi et al 2019). In general, the use of SS316L electrode plates measuring $100 \times 100 \mathrm{~mm}$ arranged in 5 cells with an input voltage of 12 volts DC will produce an electric current output of 10 Ampere and a flow rate of $\mathrm{HHO}$ gas $500 \mathrm{~mL} / \mathrm{min}$. In order to increase the quality and volume of HHO gas production, it can be done by increasing the surface roughness and contact angle on the electrode plate through the grinding and polishing process using grinding machines and abrasive paper or sandpapers starting with numbers 800, 1200 and 1400 to increase the surface roughness of the electrode plate until the roughness value reaches 1 - $0.25 \mu \mathrm{m}$. The surface roughness value of the electrode plate is measured using a 3D Profilometer, a tool for measuring the roughness of the metal surface, which is carried out on two kinds of electrode plates without polishing and on the electrode plate with polishing. This condition gave different results, namely, on the electrode plate without polishing the average roughness was $0.625 \mu \mathrm{m}$ and the electrode plate with the polishing average roughness was $0.235 \mu \mathrm{m}$. Measurements were made on 8 samples of electrode plates without polishing and 8 electrode plates with polishing and a measuring point matrix on each of the 10 measuring points plates. The results show a significant difference of $30 \%$ from the surface roughness value and the resulting volume of $\mathrm{HHO}$ gas production through the calibration process carried out on the $\mathrm{HHO}$ generator is $11 \%$. From this research, it can be concluded that surface roughness has a direct effect on the volume of $\mathrm{HHO}$ gas production with the same input voltage of 12 volts DC with an electric current output of 8.86 Ampere which is relatively smaller than the electrodes plate used without polishing.

KEYWORDS: Cell Plate SS316L, Polishing Plate, Roughness Measurement, Surface Quality

Received: Jun 08, 2020; Accepted: Jun 28, 2020; Published: Sep 17, 2020; Paper Id.: IJMPERDJUN20201314

\section{INTRODUCTION}

The HHO generator as a means of producing HHO gas has begun to be developed by many researchers who carry out their research in the field of water-based hydrogen gas. Hydrogen gas as a fuel supplement for internal combustion engines obtained through the electrolysis of water is the simplest and cheapest way because water raw materials are very easy to obtain and widely available on earth, especially in tropical countries. So far, there are two types of HHO generators, namely wet cell and dry cell, and what is being developed nowadays is the dry cell model, because it has advantages over the wet cell model. Generator HHO works based on the electrolysis of water, where a catalyst dissolved in water in a reservoir is then flowed with a DC electric current through the electrode plates capable of breaking water molecules into hydrogen and oxygen gas which is called "hydroxy gas", because it 
is a mixture of hydrogen gas and oxygen gas. The next development of the HHO generator is a new concept that integrates the wet cell model with the dry cell into one in a compact format where the water reservoir and the electrode plate spacer are in one container. The HHO generator with this new concept is called a hybrid type generator.

The reasons for developing $\mathrm{HHO}$ generators as $\mathrm{HHO}$ gas producers include the growing development of transportation technology and the depletion of fossil fuels, so the need for fuel, both oil and gas, is a need that must be met by the government in the context of energy stability. New and renewable energy continues to be pursued by the Government in order to answer the aforementioned needs by disseminating the use of energy-saving and environmentally friendly technologies. Hydrogen is a new form of energy and is classified as a transportation fuel as the most promising new energy candidate for the future. Various researches of fuel cell vehicles sourced from hydrogen by the world's leading automotive industry over the past 50 years have begun to shed some light on the use of hydrogen-based fuel cells as vehicle fuels. If the results of this study provide the expected positive results, then the end of this decade will be the era of fuel cell cars around the world. At that time, there will be a huge surge in demand for hydrogen. [5]

This research discusses the process of HHO gas volume production by processing the electrode plate through a grinding and polishing process to get the surface roughness of the electrode plate in order to increase the surface area of the contact angle to produce more HHO gas with constant voltage input and relatively low electric current output and production volume. bigger $\mathrm{HHO}$ gas.

The amount of catalyst that is put into the HHO generator is directly proportional to the output of the electric current produced because the DC voltage input is constant, meaning that with the addition of a catalyst, it can increase the electric current and the volume of HHO gas production produced by the HHO generator. However, the contribution of the electrode plate has a significant effect on the volume of HHO gas production due to the treatment process on the electrode plate by expanding the surface of the electrode plate through the grinding and polishing process so that there is a homogeneous roughness on the electrode plate. The level of roughness has an influence on the volume of HHO gas production. Thus, the new energy in the form of hydrogen gas produced from the electrolysis of water provides a great opportunity for the development of new energy in developing countries for energy-saving and environmentally friendly. [4]

Some of the problems related to the volume of $\mathrm{HHO}$ gas production for HHO generators are as follows:

- $\mathrm{HHO}$ gas obtained from the $\mathrm{HHO}$ generator through the electrolysis process is a conventional technology and the results are inconsistent.

- The quality and volume of HHO gas production can be caused by the condition of the electrode plate without treatment, so that the surface roughness of the electrode plate is not homogeneous and results in HHO gas results not as expected.

- The design of the HHO generator in an effort to increase the volume of HHO gas production needs to pay attention to the dimensions and gaps between the electrode plates

- The drawback of the wet cell type HHO generator design is that the working temperature rises easily so that the quality of HHO gas is not good and contains lots of water vapor particles. Meanwhile, dry cell design requires pulse wide modulation (PWM) to control the temperature rise. If the temperature rises to a certain limit, the PWM 
will turn off the HHO generator and will operate again if the temperature drops back according to the setpoint, then the HHO gas flow will turn on and stop sending HHO gas supplies.

To overcome the above problems, the research activities will include:

- Treating the SS316L electrode plate by grinding and polishing to obtain a homogeneous level of surface roughness up to $1-0.25 \mu \mathrm{m}$.

- Integrate two types of wet cell type HHO generators with dry cells into a new generation HHO generator called a hybrid generator.

- Performing a function test, calibration, and testing of a hybrid type HHO generator, to determine the performance of the $\mathrm{HHO}$ generator through data analysis of the above measurements.

The purpose of this study was to determine the output performance of the HHO generator, both the quality and volume of $\mathrm{HHO}$ gas production by comparing the untreated electrode plate with the treated electrode plate.

\section{METHODOLOGY}

The research methodology consists of two main parts; First, the manufacturing process of the Hybrid type HHO generator starts with the treatment process on the $316 \mathrm{~L}$ stainless steel electrode plate by grinding and polishing the surface of the electrode plate using sandpaper size 800, 1000 and 1200 points per millimeter to obtain a homogeneous level of 1-0.25 $\mu \mathrm{m}$. Then the roughness measurement is carried out using a 3D Profilometer to determine the homogeneity of the surface roughness of the electrode plate, then the SS316L electrode plate is assembled into a spacer which is the heart of an HHO generator. The next process is to make a new generation hybrid type HHO generator casing using HDPE (High-Density Polyethylene) material with a length of $20 \mathrm{~cm}$, a width of $5 \mathrm{~cm}$ and a height of $30 \mathrm{~cm}$, then assembling the spacers into the HHO generator casing along with other components such as bubblers, hoses, and accessories so that they become a complete and ready to function $\mathrm{HHO}$ generator.

The second stage is to perform a function test and calibration of the HHO generator to determine its performance such as the volume of HHO gas production, DC voltage input, and HHO generator electric current output according to the design. Calibration is done by providing input voltages of $12 \mathrm{~V}, 13 \mathrm{~V}$, and $14 \mathrm{~V}$, DC to the HHO generator with the electrode plate without treatment, and the electrode plate being treated. Changes in the input from 12 volts to 13 volts onwards, the addition of a catalyst $(\mathrm{KOH})$ is also carried out in stages starting from 5 grams, 10 grams, and so on to 50 grams at each change in the input voltage from $12 \mathrm{~V}, 13 \mathrm{~V}$, and $14 \mathrm{~V}$ DC. In the implementation of this calibration, the change in output in the form of electric current (Ampere) and $\mathrm{HHO}$ gas flow is observed in units of $\mathrm{mL} /$ minute for each additional catalyst gradually.

The experiment will produce data measuring the amount of electric current and the time it takes to produce the volume of HHO gas in liters per minute. Figure 1. Shows the schematic diagram of HHO generator production process. 


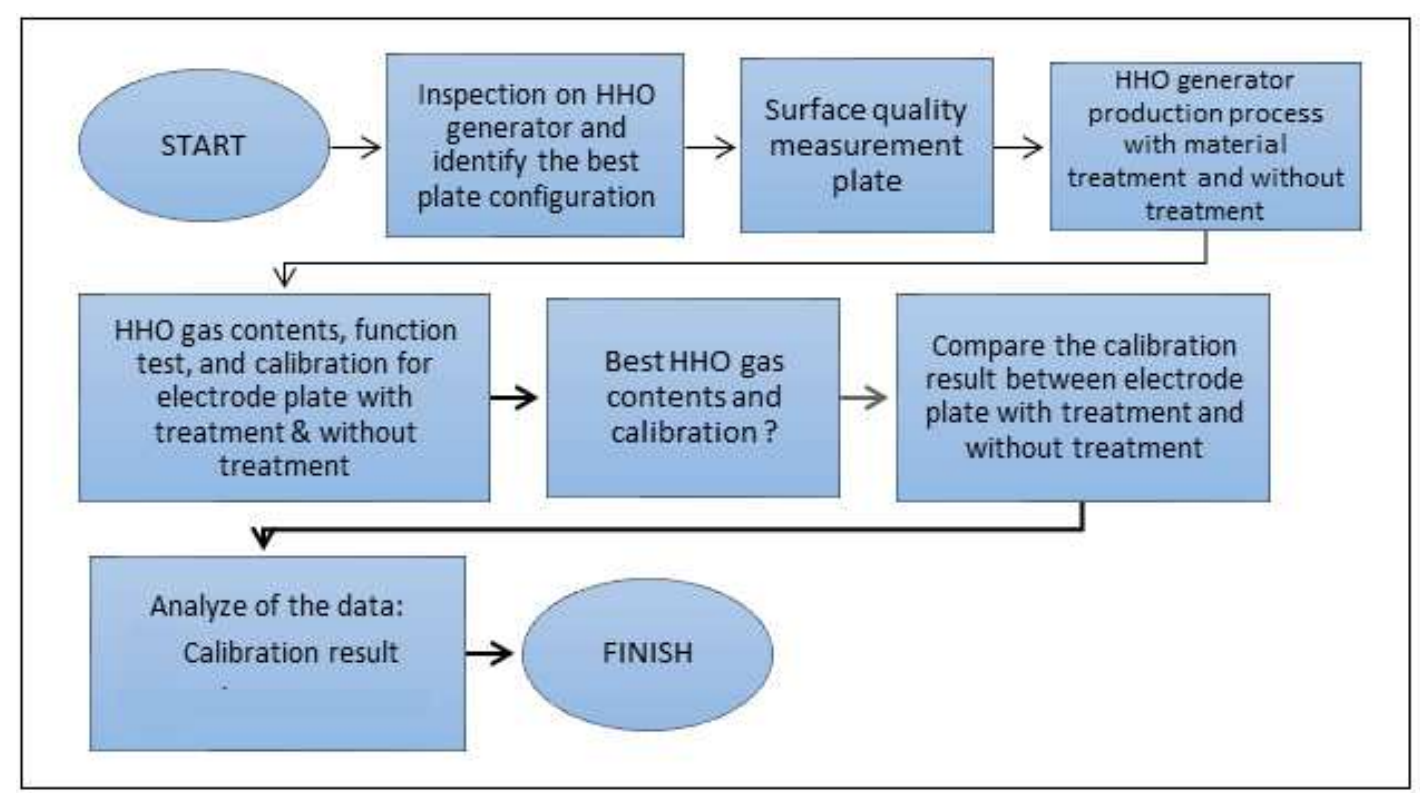

Figure 1: Schematic Diagram of HHO Generator Production Process.

\section{RESULT}

Based on the methodology described above, this section presents the results that have been analyzed regarding the production of hybrid type $\mathrm{HHO}$ generators that combine wet cell and dry cell types into a new concept of hybrid type HHO generators. The discussion includes the process of measuring the surface roughness of the electrode plate using a noncontact 3D profilometer because the measurement results are accurate and the sample surface will not be damaged. The design and manufacture of hybrid HHO generators with a new concept and without treatment and electrode plates with the treatment process is a new phenomenon of an HHO generator with the concept of widening the cross-sectional area of the electrode plates through the treatment of plate surface roughness. The function test and calibration of the HHO generator are carried out to determine the performance and characteristics of the HHO generator in producing the quality and volume of $\mathrm{HHO}$ gas production.

The measurement results of the electrode plate and the calibration of the HHO generator are recorded and analyzed and the results are presented in the form of graphs and data tables that show the comparison of the results obtained on the electrode plate with the treatment process and the electrode plate without treatment.

\section{ROUGHNESS MEASUREMENT}

Measurement of the surface roughness of the electrode plate is carried out by a non-contact 3D profilometer, where 10 points are read on each electrode plate. Surface roughness measurements using the 3D Non-Contact Profilometer are more effective because to determine roughness parameters can be done in three dimensions and the measurement process on the electrode plate sample is very accurate compared to conventional methods because the sample surface will not be damaged. Figure 2 shows the measurement result of Ra's value by using a 3D Profilometer at surface roughness measurement of the SS316L electrode cell plate. 


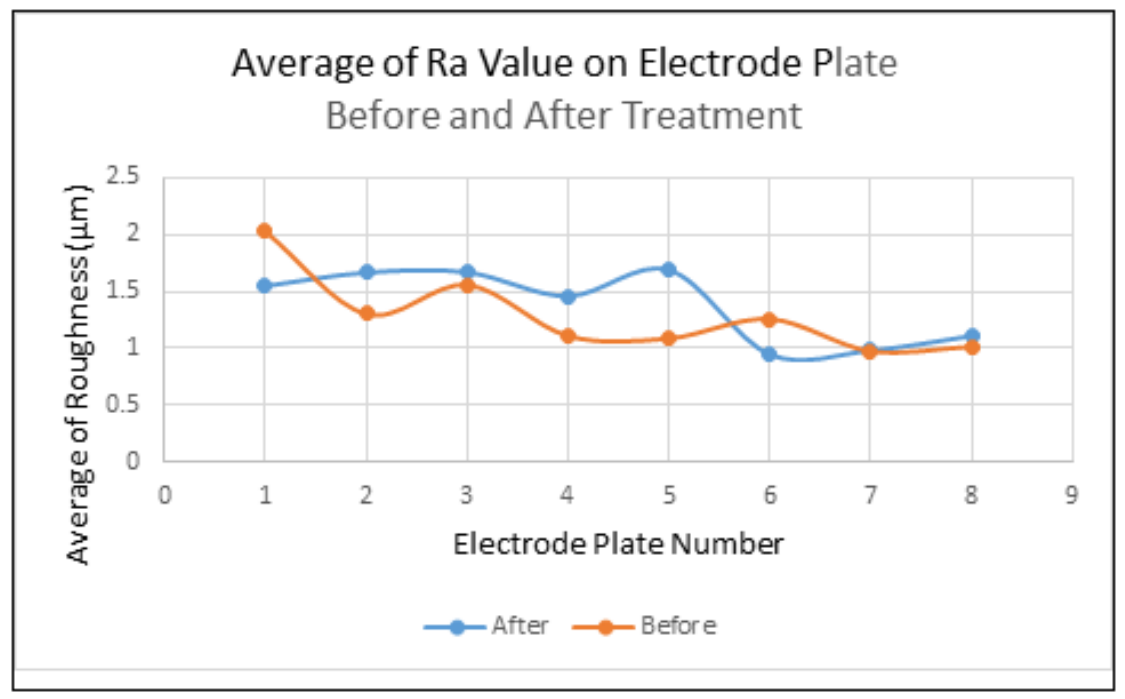

Figure 2: The Measurement Result of Ra Value by using a 3D Profilometer.

\section{CALIBRATION MEASUREMENT}

To find out the performance of the HHO generator before it is implemented on an internal combustion engine, it is necessary to calibrate it to match the volume of $\mathrm{HHO}$ gas required by the engine. The way to do the calibration is to provide a DC input voltage to the $\mathrm{HHO}$ generator of $12 \mathrm{~V}, 13 \mathrm{~V}$, and $14 \mathrm{~V}$, alternately and given a KOH catalyst to the $\mathrm{HHO}$ generator in stages starting from 5 grams, 10 grams and up to 50 grams for each given input voltage. The output observed is the variation of electric current at each addition of the $\mathrm{KOH}$ catalyst and the flow of $\mathrm{HHO}$ gas produced from the HHO generator.

HHO generator calibration results data are displayed in the form of tables and graphs that represent data from electrode plates without treatment and electrode plates with treatments. The results of the two-calibration data were compared to determine the pattern of characteristics and performance of the two models of the electrode plate without treatment and the electrode plate with the treatment. The results of the HHO generator calibration are shown in Figures $3,4,5$ and table 1 below.

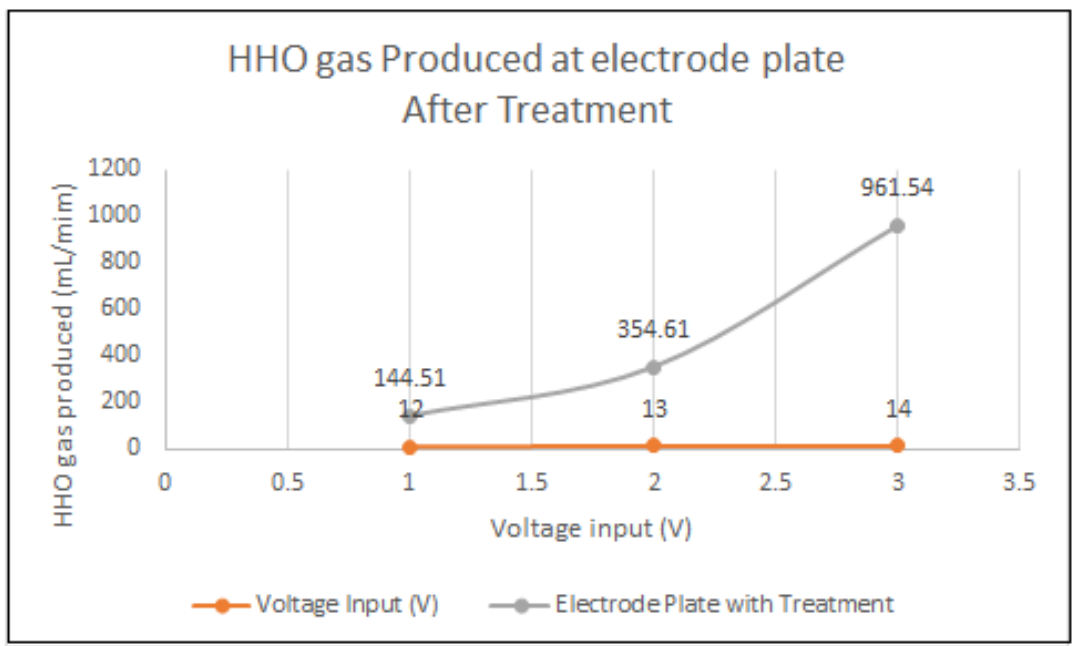

Figure 3: Graph of Increasing the Amount of HHO Gas Production to Changes in Current Flow for Treated Electrodes. 


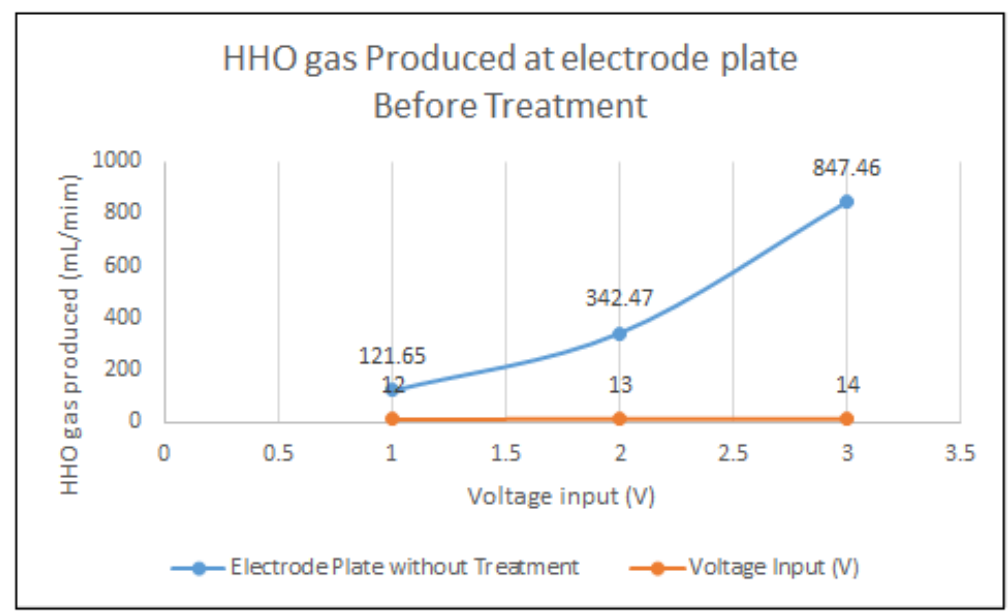

Figure 4: Graph of Increasing the Amount of HHO Gas Production to Changes in Current Flow for Untreated Electrodes.

The following is a table and graph that shows the relationship of input voltage to the production of HHO gas in treated materials and untreated a material.

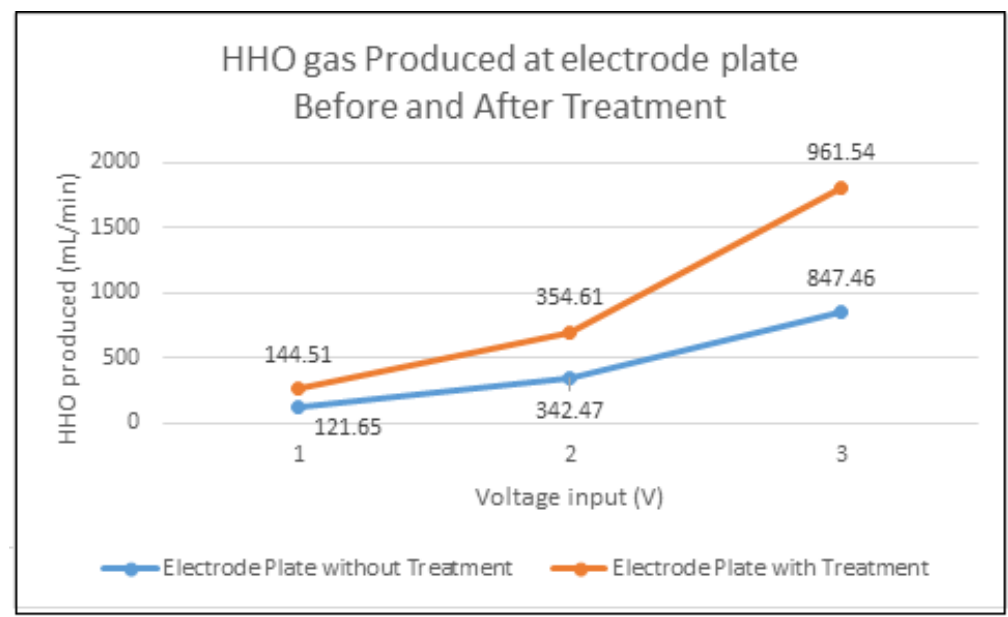

Figure 5: Graph of Comparison of the Amount of HHO Gas Production between Treated Material and Untreated Material.

Table 1: Voltage Inputs to HHO Gas Production in Treated Materials and Untreated Materials

\begin{tabular}{|c|c|c|}
\hline $\begin{array}{c}\text { Voltage Input } \\
\text { (V) }\end{array}$ & \multicolumn{2}{|c|}{ HHO gas production volume $(\mathrm{mL} / \mathrm{min})$} \\
\cline { 2 - 3 } & $\begin{array}{r}\text { Electrode Plate } \\
\text { with Treatment }\end{array}$ & $\begin{array}{r}\text { Electrode Plate } \\
\text { without Treatment }\end{array}$ \\
\hline 12 & 144.51 & 121.65 \\
\hline 13 & 354.61 & 342.47 \\
\hline 14 & 961.54 & 847.46 \\
\hline
\end{tabular}

\section{DISCUSSIONS}

Referring to Figure 2, the average roughness on the surface of the electrode plate shows a significant difference in the electrode plate with the treatment process and without treatment. The significant average Ra value indicates that the rough surface area of the electrode plate has an impact on increasing the volume of HHO gas produced by the HHO generator. 
The difference in results is due to the electrode plate having a larger surface area than the untreated electrode plate in producing $\mathrm{HHO}$ gas.

Effect of SS316L plate surface roughness on volume HHO gas production as follows:

- A hybrid type HHO generator, using two types of treated stainless steel electrode plates (SS316L) and untreated electrodes. The results obtained on the treated electrode obtained the highest surface roughness of $0.68 \mu \mathrm{m}$ and the lowest $0.189 \mu \mathrm{m}$.

- Calibration of the HHO generator with the above conditions is carried out at the input voltage of $12 \mathrm{~V}, 13 \mathrm{~V}, 14$ $\mathrm{V}, \mathrm{DC}$ by adding a catalyst $(\mathrm{KOH})$ in stages starting from 5 grams, 10 grams and so on to 50 grams.

Figure 3 shows the characteristics of $\mathrm{HHO}$ gas produced from an $\mathrm{HHO}$ generator using electrode plates with treatments. The graph explains that the increase in the volume of $\mathrm{HHO}$ gas is based more on changes in the output of electric current caused by changes in the input voltage of $12 \mathrm{~V}, 13, \mathrm{~V}$ and $14 \mathrm{~V}$. The change in input voltage changes the output electric current along with the addition of a catalyst $(\mathrm{KOH})$ every 5 grams and results in an increase HHO gas production volume in $\mathrm{HHO}$ generators. In the graph, it can be seen that the volume of HHO gas production increases by $144.51 \mathrm{~mL} /$ minute, $354.61 \mathrm{~mL} /$ minute and $961.54 \mathrm{~mL} /$ minute with variations in flow changes of $3.342 \mathrm{~A}, 5.602 \mathrm{~A}$, and 8,594 A. The increase in the volume of HHO gas production is strongly influenced by the surface roughness of the electrode plate which increases the cross-sectional area of the larger contact angle when compared to the untreated electrode plate.

Graph in Figure 4 shows that the electrode plate without treatment has the same properties as the electrode plate with treatments, namely, it is sensitive to a given input voltage and a response to the output of an electric current. The addition of a catalyst to the HHO generator is directly proportional to increasing the flow rate of HHO gas produced from the HHO generator, it's just that because the electrode plates are without treatment, the production volume produced from the $\mathrm{HHO}$ generator is lower than the $\mathrm{HHO}$ generator with electrode plates with treatments. In this experiment, the electrode plate without treatment produced a maximum electric current of 8038 A with 50 grams of $\mathrm{KOH}$ catalyst and a volume of HHO gas production of $847.45 \mathrm{~mL} /$ minute.

With referring to the above conditions, at a maximum input voltage of $14 \mathrm{~A}$ for each plate with maintenance and without maintenance, it can be concluded that the treated plate has an increase in the volume of HHO gas production by $11 \%$.

\section{CONCLUSIONS}

- Hybrid type HHO generator, using two types of treated stainless steel electrode plates (SS316L) and untreated electrodes. The results obtained on treated electrodes obtained the highest surface roughness of $0.68 \mu \mathrm{m}$ and the lowest of $0.189 \mu \mathrm{m}$.

- Calibration of the HHO generator with the above conditions is done at the input voltage of $12 \mathrm{~V}, 13 \mathrm{~V}, 14 \mathrm{~V}, \mathrm{DC}$ by adding a catalyst $(\mathrm{KOH})$ in stages starting from 5 grams to 50 grams, and the result is that on the electrode plate without treatment obtained $847.46 \mathrm{~mL} / \mathrm{min}$ and plates electrodes with treatment obtained $961.54 \mathrm{~mL} / \mathrm{min}$.

- Referring to the above conditions, at the maximum input voltage of $14 \mathrm{~A}$ for each plate with treatments and without treatments, it can be concluded that the treated plate has an increase in the volume of HHO gas production by $11 \%$. 


\section{ACKNOWLEDGEMENT}

The author would like to acknowledge, Green Tribology and Engine Performance (GTriBoE) Research Group, Research on Energy (CARe) Center, Faculty of Mechanical Engineering, UTeM and Faculty of Engineering \& Science, Universitas Nasional- Jakarta, Indonesia (UNAS) for continuous support in this study.

\section{REFERENCES}

1. Lodhi, M.J.K., Deen, K.M., Greenlee-Wacker, M.C. and Haider, W., 2019. Additively manufactured 316L stainless steel with improved corrosion resistance and biological response for biomedical applications. Additive Manufacturing, 27, pp.8-19.

2. Hussain, G., Sofianos, M.V., Lee, J., Gibson, C., Buckley, C.E. and Silvester, D.S., 2018. Macroporous platinum electrodes for hydrogen oxidation in ionic liquids. Electrochemistry Communications, 86, pp.43-47.

3. De Silva, T.S., Senevirathne, L. and Warnasooriya, T.D., 2015. HHO generator-an approach to increase fuel efficiency in spark ignition engines. European journal of Advances in Engineering and Technology, 2(4), pp.1-7.

4. Al-Rousan, A.A., 2010. Reduction of fuel consumption in gasoline engines by introducing HHO gas into intake manifold. International journal of hydrogen energy, 35(23), pp.12930-12935.

5. Rosley, M.N., Tamaldin, N., Abdollah, M.F., Zakaria, M.Z., Yamin, M. and Kamal, A., 2006. Emission characteristics of hydrogen enrichment in light duty single cylinder diesel engine. ARPN Journal of Engineering and Applied Sciences, 12, pp.4255-4258.

6. Sudrajat, A., Tamaldin, N., Kamal, A. and Abdollah, M.F.B., 2018. Optimization of HHO generator zero current leak cell (ZCLC) model characteristics for improve gas productivity. Proceedings of Mechanical Engineering Research Day, 2018, pp.3-5.

7. Sudrajat, A., Handayani, E.M., Tamaldin, N. and Yamin, A.K.M., 2018. Principle of generator HHO hybrid multistack type production technologies to increase HHO gas volume. In SHS Web of Conferences (Vol. 49, p. 02016). EDP Sciences.

8. Rosley, M.N., Tamaldin, N., Abdollah, M.F.B., and Zulfattah, Z.M., 2015. The Effects of Voltage Flow and pH Value in Alkaline electrolyser System to Performance. In Applied Mechanics and Materials (Vol. 773, pp. 440-444). Trans Tech Publications Ltd.

9. Biswajit Jena, S.Z Khan, Bipin Bihari Mohanty \& Swati Surabhi, "Experimental Study on Effect of Fiber Orientation on the Tensile Properties of Fabricated Plate Using Carbon Fiber “, International Journal of Civil Engineering (IJCE), Vol. 5, Issue 4, pp.9-16

10. Mohammad S. Alsoufi \& Mohammed Yunus, "Effect of Heat Treatment on Stress Corrosion Cracking Resistance of Al-ZnMg-Cu Alloy Used in Aerospace Engineering Applications “, BEST: International Journal of Management, Information Technology and Engineering (BEST: IJMITE), Vol. 3, Issue 8, pp. 19-34

11. Innocent Uduehi Abhulimen, "Evaluation of the Hardness and Microstructure of a Tungsten Inert Gas Weld of a Mild Steel Pipe Joint “, IMPACT: International Journal of Research in Engineering \& Technology (IMPACT: IJRET), Vol. 2, Issue 8, pp. $117-126$

12. Rishipal, Swarna Torgal, M.P. Kamath \& A.S. Joshi, "Simple Technique for Fabrication of Toroidal Surface with a Bender and Cylindrical Polishing Machine “, International Journal of Mechanical Engineering (IJME), Vol. 6, Issue 4,pp. 15-26 